University of Nebraska - Lincoln

DigitalCommons@University of Nebraska - Lincoln

Nebraska Cooperative Fish \& Wildlife Research Nebraska Cooperative Fish \& Wildlife Research Unit -- Staff Publications

2001

Nonlethal Methods of Examining Fish Stomach Contents

Jan F. Kamler

Texas Tech University

Kevin L. Pope

Texas Tech University, kpope2@unl.edu

Follow this and additional works at: https://digitalcommons.unl.edu/ncfwrustaff

Part of the Other Environmental Sciences Commons

Kamler, Jan F. and Pope, Kevin L., "Nonlethal Methods of Examining Fish Stomach Contents" (2001). Nebraska Cooperative Fish \& Wildlife Research Unit -- Staff Publications. 55.

https://digitalcommons.unl.edu/ncfwrustaff/55

This Article is brought to you for free and open access by the Nebraska Cooperative Fish \& Wildlife Research Unit at DigitalCommons@University of Nebraska - Lincoln. It has been accepted for inclusion in Nebraska Cooperative Fish \& Wildlife Research Unit -- Staff Publications by an authorized administrator of DigitalCommons@University of Nebraska - Lincoln. 
Reviews in Fisheries Science, 9(1): 1-11 (2001)

\title{
Nonlethal Methods of Examining Fish Stomach Contents
}

\author{
Jan F. Kamler and Kevin L. Pope \\ Department of Range, Wildlife, and Fisheries Management, Texas Tech University, Lubbock, \\ TX 79409
}

\begin{abstract}
Several nonlethal methods have been developed to determine the stomach contents of fish, including gastroscopes, tubes, stomach suction, stomach flushing, emetics, forceps, and chronic fistulas. By reviewing the literature on this subject, we found that the effectiveness (ability to remove all stomach contents) of the different methods depends on size, age, species of fish, and the size of the food items in the stomach. Overall, various methods of stomach flushing were the most effective method of recovering stomach items from a variety of fishes. Mechanized pressure appeared to be the most efficient method of stomach flushing for most large fishes. The use of syringes allowed stomach flushing to be performed on most young and small fishes. The use of tubes and stomach suctions, much simpler and less expensive methods than stomach flushing, were nearly as effective for some fishes such as black bass (Micropterus spp.) and salmonids.
\end{abstract}

KEY WORDS: emetics, food habits, gastroscopes, stomach flushing, stomach tubes.

\section{INTRODUCTION}

An important component of fisheries research is determining food habits of fish. Most studies have traditionally sacrificed relatively large numbers of fish to examine their stomach contents. However, sacrificing fish for food habit studies may cause poor public relations and may not be a preferable option if study fish are threatened, endangered, economically valuable, or come from a low density population (Baker and Fraser, 1976; Crossman and Hamilton, 1978; Light et al., 1983; Haley, 1998). Additionally, lethal methods may significantly alter the population structure of fish in some areas (Light et al., 1983; Hartleb and Moring, 1995). Therefore, several nonlethal methods were developed over the last 70 years to assess food habits of fish. Nonlethal methods include the use of gastroscopes, tubes, stomach suction, stomach flushing, emetics, forceps, and chronic fistulas.

This article reviews, describes, and compares these methods. The effectiveness (ability to remove all stomach contents) of each method is described if reported. The extent to which each method is used and the advantages and disadvantages of each are discussed.

$1064-1262 / 01 / \$ .50$

(C)2001 by CRC Press LLC 


\section{GASTROSCOPES}

Gastroscopes are long metal cones that are inserted into the mouth of a fish through the pharynx and into the anterior end of the stomach. The major food items in the stomach of the fish can then be visually discerned and recorded (Dubets, 1954). The use of gastroscopes to determine the diets of live fish was first employed by Dubets (1954) on largemouth bass (Micropterus salmoides).

Several researchers have reported using gastroscopes to obtain food material from the stomachs of largemouth bass, although the exact method for removing the food items was not stated (Lewis et al., 1974; Summers, 1980). Wright (1970) used forceps in concurrence with gastroscopes to remove stomach contents of largemouth bass. Other devices, such as acrylic tubes, have been used as gastroscopes to view stomach contents without removing them (Van Den Avyle and Roussel, 1980; Guy and Willis, 1993).

Gastroscopes are probably the simplest and least invasive of all the methods. However, gastroscopes may be inadequate for detailed analysis of the entire stomach contents (Foster, 1977), and may be biased toward larger food items. The effectiveness of gastroscopes to determine diets of fish has not been evaluated.

\section{TUBES}

White (1930) was the first to describe the use of tubes to obtain stomach contents of fish. White (1930) inserted a glass tube of suitable size into the gullet of eastern brook trout (Salvelinus fontinalis) and then exerted pressure over the stomach. The stomach contents were forced through the tube into a dish. White (1930) stated that to remove the entire stomach content it was sometimes necessary to inject water into the stomach through the tube and then force the water out. Glass tubes were also used to obtain the stomach contents of walleye (Stizostedium vitreum), white crappie (Pomoxis annularis), yellow perch (Perca flavescens), largemouth bass, spotted bass (M. punctulatus), striped bass (Morone saxatilis), white bass (M. chrysops), and striped X white bass hybrids (Forney, 1974; Colle, 1976; Neiman, 1978; Clady, 1980; Gilliland et al., 1981). Gilliland et al. (1981) evaluated the effectiveness of this method and found that it removed the entire stomach contents from $100 \%$ of striped bass, $95 \%$ of striped X white bass hybrids, $90 \%$ of white bass, and $75 \%$ of white crappie. The poorer results from white crappie were probably due to the presence of a small down-turned pouch at the posterior end of the stomach (Gilliland et al., 1981).

More recent studies have used acrylic tubes instead of glass tubes (Van Den Avyle and Roussel, 1980; Cailteux et al., 1990; Guy and Willis, 1993). Acrylic tubes were used to obtain stomach contents of largemouth bass, spotted bass, smallmouth bass (M. dolomieu), and white crappies (Van Den Avyle and Roussel, 1980; Cailteux et al., 1990; Guy and Willis, 1993).

Van Den Avyle and Roussel (1980) and Cailteux et al. (1990) evaluated the use of a stomach sampler that consisted of a series of acrylic tubes with different diameters. Van Den Avyle and Roussel (1980) found that only 1 out of 266 bass (spotted bass, smallmouth bass, and largemouth bass) contained food after tubes 
were used. Cailteux et al. (1990) had greater than $80 \%$ recovery by weight of foods that were obtained with acrylic tubes from largemouth bass ranging in size from 100to $590-\mathrm{mm}$ total length.

The use of acrylic tubes appears to be relatively efficient in obtaining the stomach contents of fish. However, there are limitations involving fish size, food size, and incomplete recovery (Van Den Avyle and Roussel, 1980; Cailteux et al., 1990). For example, the tubes are most effective on largemouth bass when used on individuals $>120 \mathrm{~mm}$ (Cailteux et al., 1990) and least effective on fish with relatively small mouths and large stomachs (Van Den Avyle and Roussel, 1980).

\section{STOMACH SUCTION}

Robertson (1945) first described the use of a suction bulb, attached to a glass tube, to collect the stomach contents of fish. The open end of the tube was inserted into the stomach of the fish through the mouth. The pressure on the bulb was then released and the stomach contents were suctioned into the tube. Robertson (1945) evaluated this method for trout by sacrificing and examining individuals after the suction was performed. This method was relatively effective, as 12 of 16 trout had no additional food items in their stomach, and the remaining 4 had only small amounts. In a study of gastric evacuation of brown trout (Salmo trutta) in captivity, Elliot (1972) used this method to obtain stomach contents. Elliot (1972) also evaluated this method by sacrificing some of the fish after being suctioned. The method was found to be $100 \%$ effective in removing stomach contents of the fish. In contrast, Foster (1977) evaluated and compared this method with other methods of obtaining stomach contents of live fish and found that it was $67 \%$ effective for the complete removal of stomach contents from largemouth bass and only $41 \%$ effective for grass pickerel (Esox americanus vermiculatus).

This method is relatively simple; however, it may be ineffective if the stomach contents of the fish are relatively large (Robertson, 1945) or if the study fish are relatively small (e.g., $<3 \mathrm{~cm}$ ). Additionally, this method is somewhat laborious, and stomach contents may be damaged when transferring the suctioned contents into another container (Kuthalingham, 1961).

Kuthalingham (1961) developed a more complicated method of suctioning food contents from the stomachs of fish. An aspirator emptied the air out of a glass tube that was connected to a rubber nozzle. The rubber nozzle was inserted into the mouth of the fish and the continuous suction of uniform pressure facilitated the transfer of the stomach contents into the glass tube (Kuthalingham, 1961). The effectiveness of this method was not evaluated.

\section{STOMACH FLUSHING}

Stomach flushing, or gastric lavage, has been a widely used technique for obtaining the stomach contents of live fish (Hyslop, 1980). There are several different techniques and various types of equipment that are used to flush out the stomach contents of fish. Stomach flushing equipment has been categorized under hand 
pumps, mechanized pressure, or syringes, although there is some overlap with these groupings.

\section{A. HAND PUMPS}

Seaburg (1957) first described the use of a stomach pump to obtain the stomach contents of live fish. Two copper tubes of different diameters were soldered together and bent at the end for easy access into the esophagus of a fish. The opposite end of the larger tube was fitted into a specimen bottle. Water was pumped through the smaller tube into the stomach of the fish by means of a rubber suction bulb with a check valve at each end for a unidirectional flow. The stomach contents were washed through the larger tube into the attached specimen bottle (Seaburg, 1957). This method has been used successfully on a variety of fish species, including bluegill (Lepomis macrochirus), pumpkinseed (L. gibbosus), black crappie (P. nigromaculatus), northern pike (Esox lucius), walleye, largemouth bass, black bullhead (Ictalurus melas), and yellow perch (Seaburg and Moyle, 1964; Johnson, 1977).

Seaburg (1957) evaluated the effectiveness of this method by sacrificing some of the fish after the stomach flushing was performed. Of 25 yellow perch, 15 walleye, and 5 smallmouth bass sacrificed, food remains were found only in one perch. Twenty fish were monitored for $24 \mathrm{~h}$ after the stomach flushing, and no mortalities were observed. In contrast, Foster (1977) evaluated and compared this method with other methods of obtaining stomach contents of live fish, and found that it was only $60 \%$ effective for removal of complete stomach contents from largemouth bass and $50 \%$ effective for grass pickerel.

Andreasson (1971) described a simplified Seaburg pump (Seaburg, 1957) to determine the diets of Central European sculpin (Cottus gobio) and brown trout. Andreasson simplified the Seaburg pump by using an india-rubber bulb with a glass tube. He evaluated the efficiency of this method by dissecting some of the fish and found it to be adequate. Gengerke et al. (1973) also modified Seaburg's stomach pump by using semirigid polyethylene tubing held by epoxy glue rather than copper tubing soldered together. Gengerke et al. (1973) evaluated the effectiveness of this modification and found no food remains in the stomachs of fish after stomach flushing. Gengerke et al. (1973) stated that this method had been used on nine species of fish without any operational difficulties. Swenson and Smith (1973) used fired-glass tubes with a stomach pump. Fired-glass tubes prevented damage to the stomach lining and allowed visual observation for completeness of pumping (Swenson and Smith, 1973).

A disadvantage of these stomach-flushing techniques is that they may be too large for fish $<10 \mathrm{~cm}$ (Strange and Kennedy, 1981). Therefore, Strange and Kennedy (1981) developed a much smaller and simpler device for juvenile and other small fish. A small Pasteur pipette was attached to a rubber tube leading to a small hand bulb equipped with one-way valves, and finally leading to a water reservoir. Fish were anaesthetized and held ventral surface up, with the head inclined downward over a collection bowl. The Pasteur pipette was then placed in the mouth of the fish and short pulses of water were pumped into the stomach to flush-out food items. Strange and Kennedy (1981) evaluated the effectiveness of this technique on brown 
trout and Atlantic salmon (Salmo salar) by sacrificing 49 fish after the flushing of stomachs. This method was 99\% effective (based on total stomach contents without accounting for individual fish) in removing stomach contents of salmon.

Wasowicz and Valdez (1994) modified the method of Gengerke et al. (1973) for roundtail chub (Gila robusta). As members of the genus Gila have a simple s-shaped intestine and lack a pyloric sphincter, this method did not use an exit tube or backpressure, but instead flushed the food items out the vent of the fish. Wasowicz and Valdez (1994) stated that stomach contents were evacuated through the vent with relatively little water pressure, and that visual examination of the entire gut tract showed no noticeable signs of injuries. Wasowicz and Valdez (1994) evaluated this method and found it to be $100 \%$ effective.

\section{B. MECHANIZED PRESSURE}

Mechanized pressure is perhaps the most recently developed method for obtaining the stomach contents of fish. Foster (1977) was the first to describe the use of mechanized pressure to obtain the stomach contents of fish. This stomach-flushing method, called pulsed gastric lavage, consisted of a hypodermic needle and a polyethylene tube, coupled with a water pump by a variable pressure valve. The size of the needle and tube was adjusted to the size of the fish. Fish were anesthetized and placed horizontally in a fine-mesh net, and then the polyethylene tube was inserted through the mouth into the stomach. The adjustable valve was then opened and closed to allow pulses of water under pressure to pass into the stomach. The water pressure would flush the stomach contents through the esophagus and into the net (Foster, 1977).

Foster (1977) evaluated and compared this method to Seaburg's (1957) method of stomach flushing, the suction pump method (Robertson, 1945), and the use of emetics (Jernejcic, 1969). Pulsed gastric lavage was found to be nearly 100\% effective for removing the complete stomach contents from grass pickerel and largemouth bass. This method was followed by Seaburg's (1957) method of stomach flushing (55\% effective at removing complete stomach contents) and the suction pump method ( $54 \%$ effective at removing complete stomach contents). Least effective was use of emetics ( $41 \%$ effective at removing complete stomach contents). Light et al. (1983) evaluated Foster's (1977) method for brook trout and slimy sculpin (Cottus cognatus) and found it to be nearly 100\% effective (based on total stomach contents without accounting for individual fish).

Crossman and Hamilton (1978) used a similar but slightly modified technique for obtaining stomach contents of muskellunge (E. masquinongy) and largemouth bass. This method included the use of a 12-volt portable pump. Gurtin (1996) also used Crossman and Hamilton's (1978) method for obtaining stomach contents of northern pike (E. lucius) and largemouth bass.

Hartleb and Moring (1995) modified Foster's (1977) apparatus to simplify the design and decrease the cost. This method included the use of hose clamps with a quick-disconnect fitting for greater speed when changing the size of the tubing. Additionally, a trough was used to collect flushed contents of stomachs for more efficient analysis of prey items under field conditions (Hartleb and Moring, 1995). Hartleb and Moring (1995) evaluated this method for several species of fish and 
found it be $100 \%$ effective with no mortality on yellow perch, largemouth bass, pumpkinseed, and white perch (M. americana). However, this method was only 75\% effective at removing the complete stomach contents for brown bullheads, and difficulty was experienced in dislodging large food items. Additionally, it was ineffective for removing the stomach contents of chain pickerel (E. niger), which may have been due to the constricted digestive systems in small specimens. The method also caused 60\% mortality in golden shiners (Notemigonus crysoleucas) and was ineffective at removing their stomach contents (Hartleb and Moring, 1995).

Hartleb and Moring (1995) concluded that the advantages of this method were low costs, ease of operation for one person, efficiency of removing stomach contents, and durability and portability of the apparatus. The main disadvantage was that the apparatus could only sample fish $>14 \mathrm{~cm}$, although the use of smaller pipettes may alleviate this problem.

\section{SYRINGES}

Syringes are often used to obtain stomach contents of relatively small fish when the apparatus from other methods is too large. Baker and Fraser (1976) first described the use of syringes to obtain the stomach contents of small fish. A short tube was inserted through the anus into the intestine of the fish. Water was injected through the tube with a hypodermic needle and the gut and stomach contents were flushed out through the mouth. Baker and Fraser (1976) evaluated the effectiveness of this method on several species of fish. This method was $97.1 \%$ effective at removing all stomach contents on mummichog (Fundulus heteroclitus), 92\% effective on creek chub (Semotilus atromaculatus), and 80\% effective on blacknose dace (Rhinichthys atratulus). However, it was less than 50\% effective at removing all stomach contents from individual white sucker (Catostomus commersoni), rosyface shiner (Notropis rubellus), brown bullhead (I. nebulosus), yellow perch, smallmouth bass, and goldfish (Carassius auratus).

Syringes have also been used to directly inject water into the stomach of fish through the mouth and esophagus (Aho, 1976; Meehan and Miller, 1978). When the water was forced into the stomach, the stomach contents were flushed back through the esophagus and mouth, through a funnel into a collecting jar. Meehan and Miller (1978) evaluated this technique on young salmonids. This method removed 99\% of stomach contents (mean of percent number flushed from each fish) from coho salmon (Oncorbynchus kisutch), 92\% from cutthroat trout (Salmo clarki), and 90\% from rainbow trout (Oncorbynchus mykiss).

Giles (1980) constructed a device that used two sizes of syringes, a plastic tube, and interchangeable rubber tubes to collect the stomach contents of fish through the esophagus. Water was forced into the stomach by the smaller syringe $\left(20 \mathrm{~cm}^{3}\right)$ through a plastic tube. The plastic tube was encased within a rubber tube that led to a larger syringe $\left(50 \mathrm{~cm}^{3}\right)$ for the collection of the stomach contents. Giles (1980) evaluated the effectiveness of this technique by sacrificing 50 perch after their stomachs were sampled. This method collected $99 \%$ of the stomach contents of the 
fish. Giles (1980) also noted that released fish were found in good condition after subsequent recaptures.

Culp et al. (1988) designed a system for obtaining stomach contents of small fish. The apparatus consisted of syringes, polyethylene tubes, flushing trough, and collection vial. The diameter of the tubes was dependent on size of the fish. This system could obtain stomach contents by anal backwashing for fish species with no pyloric sphincter, or by stomach flushing through the esophagus for species with a pyloric sphincter (Culp et al., 1988). Culp et al. evaluated this method and found it to be nearly $100 \%$ effective for removal of complete stomach contents from both longnose dace (Rhinichthys cataractae) and rainbow trout.

Although syringes may be effective for some species of fish, they may be ineffective and even fatal in other species. For example, tubing and a syringe was used to obtain stomach contents from juvenile white sturgeon (Acipenser transmontanus) (Sprague et al., 1993 - cited in Haley, 1998). However, a 33\% mortality rate was observed in 1 week of sampling. Sprague et al. (1993) concluded high water pressures associated with stomach flushing harmed juvenile white sturgeon by rupturing swim bladders and causing other internal injuries.

Haley (1998) developed a method to safely obtain stomach contents of sturgeon. This method consisted of a syringe and intramedic tubing that was carefully inserted into the digestive tract. Haley (1993) recovered food from $91 \%$ of the juvenile Atlantic sturgeon (Acipenser oxyrinchus) and $81 \%$ of the shortnose sturgeon (Acipenser brevirostrum) that she sampled; however, she made no attempt to evaluate the effectiveness of this method.

\section{EMETICS}

Emetics are drugs or chemical solutions that induce regurgitation. Markus (1932) first described the use of emetics to obtain the stomach contents of fish. Markus (1932) injected a solution of arsenous acid and hydrochloric acid into the stomachs of largemouth bass. The bass were then placed into an aquarium and the stomach contents were collected from the bottom.

Jernejcic (1969) compared the use of three emetics (arsenous acid, tartar, and apomorphine) on walleye. Jernejcic (1969) found that tartar was most effective, followed by arsenous acid. Apomorphine was least effective. Jernejcic (1969) suggested that antimony might also work effectively as an emetic for fish. The effectiveness of other emetics to obtain all stomach contents of fish has not been evaluated. Foster (1977) evaluated and compared the use of tartar with other methods of obtaining stomach contents of live fish and found that it was $69 \%$ effective at removing complete stomach contents from largemouth bass and only $12 \%$ effective for grass pickerel.

The use of emetics may have several disadvantages. The use of arsenous acid may leave trace amounts of arsenic in the fish (Markus, 1932). Additionally, emetics may not work on all species of fish. For example, Mason and Clugston (1993) found emetics to be unsuccessful for gulf sturgeon (Acipenser oxyrinchus desotoi). 


\section{FORCEPS}

The use of forceps to directly obtain the stomach contents of trout has been reported (Wales, 1962). This method is simple, although the fish have to be anesthetized (Wales, 1962). Forceps have also been used in concurrence with gastroscopes to obtain stomach contents of largemouth bass (Wright, 1970). The effectiveness of using forceps to obtain stomach contents has not been evaluated.

\section{CHRONIC FISTULAS}

The installation of chronic fistulas in the digestive tract of fish has been reported (Krayukhin, 1962 — cited in Foster, 1977). However, it is doubtful if such a method would be applicable in field studies. The effectiveness of chronic fistulas to determine fish diets has not been evaluated.

\section{RECOMMENDATIONS}

The effectiveness of the different nonlethal methods for determining fish diets varied, and depended on the size, age, and species of fish, and the size of the food items in the stomach. Overall, stomach flushing was the most effective method of obtaining stomach contents from most fishes. Different stomach-flushing techniques were used on a variety of fish. Mechanized pressure appeared to be the most effective method of stomach flushing for most species. The use of syringes allowed stomach flushing to be performed on most young and small fishes, however, special modifications must be made for some species such as sturgeon. The use of tubes and stomach suctions, much simpler and less expensive methods than stomach flushing, were nearly as effective for some fish such as black bass and salmonids. The limitations and biases associated with gastroscopes, emetics, forceps, and chronic fistulas likely prevent the widespread use of these methods for obtaining stomach contents from most species. However, a combination of methods may be more effective than any single method. For example, tubes could be used to remove stomach contents, then be reinserted into the fish for viewing the stomach to determine if all contents were removed (gastroscope). If food contents remained, they could be flushed out with water (flushing) or removed with forceps.

When determining which nonlethal method to use for a study, researchers should consider species, the probable size and age of the fish, budget constraints, and the number of personnel that will be conducting the fieldwork. These factors help determine which method or methods are best for that particular research project. However, we believe that no single method of removing stomach contents will work on all fishes or in all studies.

Surprisingly, few assessments of associated mortality rates have been conducted with most of these methods. Future investigations should determine the associated mortality rates with these various methods. Recent work revealed that tournamentassociated mortality with black bass was much greater than originally believed (Wilde, 1998). Similarly, mortality rates associated with the various methods dis- 
cussed in this article may be more substantial than currently thought. Many studies examined the effectiveness of particular methods by sacrificing fish after the removal of stomach contents and, thus, were unable to assess mortality associated with a particular method. Seaburg (1957) found no mortality associated with stomach flushing in yellow perch, walleye, and smallmouth bass that were observed for 24 h. Hartleb and Moring (1995) assessed mortality associated with stomach flushing and found no mortality on yellow perch, largemouth bass, pumpkinseed, and white perch. However, neither assessment appears to consider delayed mortality beyond 24 h. Strange and Kennedy (1981) assessed the survival of salmonids subjected to stomach flushing and found no difference between stomach-flushed fish and control fish that were held for 3 to 5 nights. In contrast, Harleb and Moring (1995) documented that stomach flushing caused $60 \%$ mortality in golden shiners. Meehan and Miller (1978) found that stomach flushing caused reduced condition in hatcheryreared juvenile coho salmon, but not in wild salmon. The current literature on hooking mortality and tournament-associated mortality documents a strong positive relation between handling-induced mortality and water temperature (e.g., Muoneke and Childress, 1994; Wilde, 1998). No such assessments have been conducted on mortality associated with methods of removing stomach contents from live fish. We believe additional mortality assessments are needed for the various methods of collecting stomach contents from live fishes and suggest that effects of temperature on this mortality be evaluated.

\section{ACKNOWLEDGMENTS}

Reviews of earlier drafts of this manuscript were provided by Timothy Bonner, Mark Wallace, Gene Wilde, and Phillip Zwank. This manuscript is contribution T-9-864 of the College of Agricultural Sciences and Natural Resources, Texas Tech University.

\section{REFERENCES}

Aho, R. S. A population study of the cutthroat trout in an unshaded and shaded section of a stream. M.S. thesis, Oregon State University, Corvallis (1976).

Andreasson, S. Feeding habits of a sculpin (Cottus gobio L. Pisces) population. Rep. Inst. Freshwat. Res. Drottningholm, 51: 5-30 (1971).

Baker, A. M., and D. F. Fraser. A method for securing the gut contents of small, live fish. Trans. Am. Fish. Soc., 105: 520-522 (1976).

Bowen, S. H. Quantitative description of the diet. pp. 513-532. In: Fisheries Techniques, Second Edition. (Murphy, B. R. and D. W. Willis, Eds.). Bethesda, MD: American Fisheries Society (1996).

Cailteux, R. L., W. F. Porak, and S. Crawford. Reevaluating the use of acrylic tubes for collection of largemouth bass stomach contents. Proc. Annu. Conf. Southeast. Assoc. Fish and Wildl. Agencies, 44: 126-132 (1990).

Clady, M. D. Results of stocking young largemouth bass and spotted bass in several ratios in Oklahoma ponds. Proc. Okla. Acad. Sci., 60: 18-25 (1980).

Colle, D. E. The food habits of three centrarchids, Lepomis macrochirus (Rafinesque), Micropterus salmoides (Lacepede), and Lepomis gulosus (Cuvier) in a central Texas farm pond. M.S. thesis, Texas A\&M University, College Station (1976) 
Crossman, E. J., and J. G. Hamilton. An apparatus for sampling gut contents from large, living fishes. Env. Biol. Fish., 3: 297-300 (1978).

Culp, J. M., I. Boyd, and N. E. Glozier. An improved method for obtaining gut contents from small, live fishes by anal and stomach flushing. Copeia, 4: 1079-1082 (1988).

Dubets, H. Feeding habits of the largemouth bass as revealed by a gastroscope. Prog. FishCult., 16: 134-136 (1954).

Elliot, J. M. Rates of gastric evacuation in brown trout, Salmo trutto. Freshwat. Biol., 2: 1-18 (1972).

Forney, J. L. Interactions between yellow perch abundance, walleye predation, and survival of alternative prey in Oneida Lake, New York. Trans. Am. Fish. Soc., 103: 15-24 (1974).

Foster, J. R. Pulsed gastric lavage: an efficient method of removing the stomach contents of live fish. Prog. Fish-Cult., 39: 166-169 (1977).

Gengerke, T. W., D. G. Unkenholz, and J. G. Nickum. A modification of Seaburg's stomach sampler. Prog. Fish-Cult., 35: 142 (1973).

Giles, N. A stomach sampler for use on live fish. J. Fish Biol., 16: 441-444 (1980).

Gilliland, E. R., C. W. Kleinholz, and M. D. Clady. The efficiency of removing food items from fish with glass tubes. Proc. Tex. Chapt. Am. Fish. Soc., 4: 95-100 (1981).

Gurtin, S. D. An assessment of northern pike populations in small South Dakota impoundments. M.S. thesis, South Dakota State University, Brookings (1996).

Guy, C. S., and D. W. Willis. Food habits of white crappies in Lake Goldsmith, South Dakota. Proc. S. D. Acad. Sci., 72: 51-60 (1993).

Haley, N. A gastric lavage technique for characterizing diets of sturgeons. N. Am. J. Fish. Manage., 18: 978-981 (1998).

Hartleb, C. F., and J. R. Moring. An improved gastric lavage device for removing stomach contents from live fish. Fish. Res., 24: 261-265 (1995).

Hyslop, E. J. Stomach contents analysis - a review of methods and their application. J. Fish Biol., 17: 411-429 (1980).

Jernejcic, F. Use of emetics to collect stomach contents of walleye and largemouth bass. Trans. Am. Fish. Soc., 98: 698-702 (1969).

Johnson, F. H. Responses of walleye (Stizostedion vitreum vitreum) and yellow perch (Perca flavescens) populations to removal of white sucker (Catostomus commersoni) from a Minnesota Lake, 1966. J. Fish. Res. Board Can., 34: 1633-1642 (1977).

Kuthalingham, M. D. K. Observations on the life history and feeding habits of a plankton feeder, the rainbow sardine (Dussumeria acuta Cuv. and Val.), with a note on the method of securing the stomach contents of a live fish. J. Zool. Soc. India, 13: 24-33 (1961).

Lewis, W. M., R. Heidinger, W. Kirk, W. Chapman, and D. Johnson. Food intake of the largemouth bass. Trans. Am. Fish. Soc., 103: 277-280 (1974).

Light, R. W., P. H. Adler, and D. E. Arnold. Evaluation of gastric lavage for stomach analyses. N. Am. J. Fish. Manage., 3: 81-85 (1983).

Markus, H. C. The extent to which temperature changes influence food consumption in largemouth bass (Huro floridana). Trans. Am. Fish. Soc., 62: 202-210 (1932).

Mason, W. T., Jr., and J. P. Clugston. Foods of the gulf sturgeon in the Suwanee River, Florida. Trans. Am. Fish. Soc., 122: 378-385 (1993).

Meehan, W. R., and R. A. Miller. Stomach flushing: effectiveness and influence on survival and condition of juvenile salmonids. J. Fish. Res. Board Can., 35: 1359-1363 (1978).

Muoneke, M. I., and W. M. Childress. Hooking mortality: a review for recreational fisheries. Rev. Fish. Sci., 2:123-156 (1994).

Neiman, D. A. Some aspects of the ecology of Florida and northern largemouth bass in a thermally enriched reservoir. M.S. thesis, Oklahoma State University, Stillwater (1978).

Robertson, O. H. A method for securing stomach contents of live fish. Ecology, 26: 95-96 (1945). 
Seaburg, K. G. A stomach sampler for live fish. Prog. Fish-Cult., 19: 137-139 (1957).

Seaburg, K. G., and J. B. Moyle. Feeding habits, digestive rates, and growth of some Minnesota warmwater fishes. Trans. Am. Fish. Soc., 93: 269-285 (1964).

Sprague, C. R., L. G. Beckman, and S. D. Duke. Prey selection of juvenile white sturgeon in reservoirs of the Columbia River. In: Status and habitat requirements of the white sturgeon populations in the Columbia River downstream from McNary Dam, volume 2, pp. 229-243 (Beamesderfer, R. C., and A. A. Nigro, Eds.). Final Report of Oregon Department of Fish and Wildlife to Bonneville Power Administration, Portland, Oregon (1993).

Strange, C. D., and G. J. Kennedy. Stomach flushing of salmonids: a simple and effective technique for the removal of the stomach contents. Fish. Manage., 12: 9-15 (1981).

Summers, G. L. Food of adult largemouth bass in a small impoundment with dense aquatic vegetation. Proc. Annu. Conf. Southeast. Assoc. Fish and Wildl. Agencies, 34: 131-136 (1980).

Swenson, W. A., and L. L. Smith, Jr. Gastric digestion, food consumption, feeding periodicity, and food conversion efficiency in walleye (Stizostedion vitreum vitreum). J. Fish. Res. Board Can., 30: 1327-1336 (1973).

Van Den Avyle, M. J., and J. E. Roussel. Evaluation of a simple method for removing food items from live black bass. Prog. Fish-Cult., 42: 222-223 (1980).

Wales, J. H. Forceps for removal of trout stomach content. Prog. Fish-Cult., 24: 171 (1962).

Wasowicz, A., and R. A. Valdez. A nonlethal technique to recover gut contents of roundtail chub. N. Am. J. Fish. Manage., 14: 656-658 (1994).

White, H. C. Some observations on the eastern brook trout ( $S$. fontinalis) on Prince Edward Island. Trans. Am. Fish. Soc., 60: 101-108 (1930).

Wilde, G. R. Tournament-associated mortality in black bass. Fisheries (Bethesda), 23(10):1222 (1998).

Wright, L. D. Forage size preference of the largemouth bass. Prog. Fish-Cult., 32: 39-42 (1970). 